\title{
"ELES [OS/AS DISCENTES] SEMPRE GOSTAM, TÊM MUITA \\ EXPECTATIVA, FICAM ANSIOSOS PRA TER LOGO A DISCIPLINA": AS POSSIBILIDADES E OS IMPASSES COM O ENSINO DA SEXUALIDADE NA ESCOLA
}

Resumo: Em tempos de discursos de ódio e retaliação insistente ao trabalho com a sexualidade na educação, este artigo analisa as potencialidades e os impasses da abordagem desta temática no espaço escolar. A pesquisa se ancora nos referenciais pós-críticos e foi desenvolvida em escolas municipais de Jequié-BA que apresentam a disciplina Educação para Sexualidade na matriz curricular dos anos finais do ensino fundamental. Para a produção $e$ análise de dados foram realizadas entrevistas semiestruturadas com onze docentes que lecionam a disciplina. A existência de um componente curricular destinado ao ensino da sexualidade garante um lugar para as discussões distanciando-se das ações descontínuas e pontuais, além do que, há um envolvimento dos/as discentes com a disciplina, oportunizando espaços de diálogo, inclusive de temas como diversidade de gênero e sexual. Todavia, há $o$ risco de aprisionar os debates sobre sexualidade neste espaço, desresponsabilizando as/aos demais docentes em trabalhar com o tema.

Palavras-chaves: Educação; Sexualidade; Gênero; Formação.
Suse Mayre Martins Moreira AZEVEDO ${ }^{1}$

Universidade Estadual do Sudoeste da Bahia susiazevedo13@hotmail.com
Abstract: In times of hate speech and persistent retaliation for working with sexuality in education, this article analyzes the potentialities and the impasses of approaching this issue in the school space. The research is anchored in the post-critical referents and was developed in municipal schools of Jequié-BA that present the discipline Education for Sexuality in the curricular matrix of the final years of elementary school. For the production and analysis of data, we conducted semistructured interviews with eleven teachers who teach the discipline. The existence of a curricular component destined to the teaching of sexuality guarantees a place for the discussions distancing themselves from the discontinuous and punctual actions, besides that, there is an involvement of the students with the discipline, giving opportunities for dialogue, including themes such as gender and sexual diversity. However, there is the risk of imprisoning the debates about sexuality in this space, disowning the other teachers in working with the theme.

Keyword: Education; Sexuality; Genre; Formation.

\footnotetext{
1 Graduação em ciências biológicas, especialização em gestão ambiental e ensino de ciências e matemática, mestrado em educação cientifica e formação de professores.
} 


\section{Introdução}

A forma como ocorrem as discussões de gênero e sexualidade na escola é bastante diversificada o que a torna uma questão bastante instigante para os estudiosos dessas temáticas

O interesse por esta pesquisa parte da visão de que, na abordagem do tema sexualidade, a escola ocupa um espaço importante, embora não seja o único, para levar informações e promover reflexões e discussões que envolvem a vivência pessoal da sexualidade, especialmente dos jovens, mesmo havendo formas de controle dessa discussão. É importante entender que não cabe aos/às gestores/as e/ou professores/as a decisão de abordar ou não questões relacionadas à sexualidade na escola, pois essas circulam espontaneamente dentro e fora da sala de aula.

$\mathrm{Na}$ concepção atual de sociedade e de educação, faz-se necessário que a escola desenvolva nos/as educandos/as uma maior autonomia, levando-os/as à reflexão e à tomada de decisões nos diversos aspectos de suas vidas, voltando-se para suas necessidades e as necessidades da sociedade em que este/esta se insere. $\mathrm{O}$ conhecimento, os saberes e as informações trazidos pela escola não podem ser alijados do cotidiano desses/as educandos/as. Louro (2008b) explicita essa função quando diz que "a escola não apenas transmite conhecimentos, nem mesmo apenas os produz, mas ela, também fabrica sujeitos, produz identidades étnicas, de gênero e de classe"(p.85). Além disso, as escolas são espaços para promoção da cultura, do reconhecimento da pluralidade das identidades e dos comportamentos relativos às diferenças como um todo (BRASIL, 2007).

As pesquisas sobre a abordagem da sexualidade na escola mostram a presença de um discurso biológico e higienista, desenvolvido, sobretudo, pelos/as professores/as de Ciências e Biologia. Esse discurso gira em torno daquilo que é considerado como consequência do exercício da sexualidade, a exemplo das doenças sexualmente transmissíveis, da gravidez não planejada e do aborto. Dessa forma, essas abordagens apresentam-se muito distantes das necessidades dos/as estudantes, por ser limitado ao âmbito anatômico-fisiológico, prescritivo e preventivo.

Essa visão é fortemente reforçada pela forma como as discussões de gênero e sexualidade se apresentam nos livros didáticos. É consenso entre os/as autores/as que, embora essas discussões devam ter uma abordagem interdisciplinar ou transversal, é nos livros de Ciências e Biologia que as mesmas aparecem, e a omissão acaba atribuindo ao 
professor desta área a responsabilidade de trazer o tema à sala de aula. É fato que, comumente as questões relacionadas à sexualidade costumam ser incluídas ao final do livro, onde, normalmente, o professor não chega. Este material também sugere que a feminilidade está subordinada à dominação masculina reforçada, a partir das relações de gênero, as condições que legitimam as estruturas de poder existentes (LIRA e JOFILI, 2010; SANTOS et al., 2011; ALTMANN, 2003; SANTANA e WALDHELM, 2009; MARTINS e HOFFMANN, 2007).

Mesmo não sendo o único espaço formador em que jovens ouvem e falam sobre sexualidade, a escola deve procurar ser um espaço em que essas questões sejam discutidas de forma espontânea, sem reforçar tabus, preconceitos, medos ou estereótipos. Não podemos negar que a família, de forma geral, transfere para a escola essa função. Essas discussões precisam deixar de ser uma opção. Elas devem ser vistas como importantes para as pessoas que se encontram na escola e para isso a escola não pode se fechar ao debate.

Segundo Louro (2008b), embora presente em todos os dispositivos de escolarização, a preocupação com a sexualidade, geralmente, não é apresentada de forma aberta e sua presença independe da intenção manifesta ou dos discursos explícitos, da existência ou não de uma disciplina de "educação sexual" ou da inclusão ou não desses assuntos nos regimentos escolares. A sexualidade está na escola porque ela faz parte dos sujeitos. Ela não é algo que possa ser desligado ou algo do qual alguém possa se "despir".

De acordo com Foucault (1998), desde o século XVIII, os construtores e organizadores escolares haviam se colocado "num estado de alerta perpétuo" em relação à sexualidade daqueles que circulam na instituição escolar. $\mathrm{O}$ espaço da sala, a forma das mesas, o arranjo dos pátios de recreio, a distribuição dos dormitórios, os regulamentos elaborados para a vigilância do recolhimento e do sono, tudo fala de maneira mais prolixa da sexualidade das crianças.

Louro (2008b) complementa que as preocupações e a vigilância em relação à sexualidade não estão restritas apenas às alunas, mas a todas as pessoas que convivem na escola. Dessa forma, todas as pessoas no espaço escolar são constantemente observadas, julgadas e, muitas vezes, "condenadas” pela forma como lidam com sua sexualidade. Esse "controle" da sexualidade das pessoas mostra que há um receio de que o desenvolvimento da sexualidade das alunas sofra influência, afastando-as do que foi determinado como norma, sobretudo no que se refere à diversidade de gênero e sexual. 
O envolvimento de toda a comunidade escolar em questões voltadas para gênero e sexualidade vai muito além do que simplesmente proporcionar espaços de discussão na escola e na sala de aula. Levando-se em conta que todas as pessoas presentes no espaço da escola são, de certa forma, educadoras, é necessário conhecer a forma como essas outras pessoas lidam com essas questões, visto que convivem com as crianças e adolescentes tanto quanto as professoras e, em algumas situações, conhecem particularidades de suas vidas mais do que as próprias professoras. Essa questão passa, muitas vezes, despercebida na escola e pode refletir negativamente quando, por exemplo, um adolescente homossexual é alvo de atitudes discriminatórias e preconceituosas por essas pessoas que "circulam na escola".

Louro (2008b) destaca a importância de levar discussões a respeito da sexualidade para a escola ao afirmar que:

Gestos, movimentos, sentidos são produzidos no espaço escolar e incorporados por meninos e meninas, tornam-se parte de seus corpos. Ali se aprende a olhar e a se olhar, se aprende a ouvir, a falar e a calar; se aprende a preferir. Todos os sentidos são treinados, fazendo com que cada um e cada uma conheça os sons, os cheiros e o sabores "bons" e decentes e rejeite os indecentes; aprenda o que, a quem e como tocar ( ou, na maior parte das vezes, não tocar); fazendo com que tenha algumas habilidades e não outras (LOURO, 2008b, p. 61).

Entendo que essa ideia deve servir de alicerce para demonstrar a necessidade de discutir questões de gênero e sexualidade no espaço da escola. Outro ponto bastante discutível em relação ao reconhecimento da escola como um dos espaços importantes para a abordagem da sexualidade é que levar discussões a esse respeito para a escola seria um meio de controle e de normatização, uma forma de saber o que está se falando a respeito da sexualidade e se o que está sendo abordado está “certo"ou “errado".

Foucault (1988), ao falar sobre a incitação aos discursos, afirma que o século XVII foi o início de uma época de repressão e, para dominar o sexo no plano real, foi necessário, primeiro, reduzi-lo ao nível de linguagem. Porém, nos três últimos séculos ocorreu um processo inverso e em torno e a propósito do sexo houve uma explosão discursiva, definindo-se, porém, onde e quando não era possível falar dele. Estabeleceu-se que entre mães, filhas, educadoras, e alunas podia-se falar de sexo com tato e descrição, diante disso, surge então, a família e a escola como espaços reconhecidos para se falar de sexo.

É cabível observar que até hoje o debate sobre sexualidade na escola não se desvencilhou do propósito de controlar os impulsos e os discursos. Isso lembra o que aconteceu no século XVIII, quando o sexo se tornou, segundo Foucault (1988), uma 
questão de "polícia", onde era necessário regulá-lo por meio de discursos úteis e públicos e não pelo rigor da proibição.

Não se pode desconsiderar, porém, que, ao longo do tempo venham ocorrendo algumas mudanças significativas na sociedade as quais influenciam direta ou indiretamente nas discussões voltadas para sexualidade no espaço escolar. Louro (2008b) afirma que:

As condições de existência das instituições escolares e acadêmicas estão, certamente, em transformação. A presença maciça das meninas e mulheres nas salas de aula; a maior visibilidade dos sujeitos homossexuais e bissexuais e seu reconhecimento pela mídia; a imposição das discussões sobre sexo e sexualidade, a partir da expansão da AIDS; o aumento das relações afetivas e sexuais fora do casamento formal; a extraordinária revolução das formas e meios de comunicaçãotodos esses e muitos outros processos estão atravessando a escola (LOURO, 2008b, p. 119-20).

Dessa forma, a escola não pode permanecer indiferente a essas questões. É importante que se realize um trabalho com planejamento e intensas discussões, com uma proposta transformadora e renovadora, pensando no bem-estar dos indivíduos que nela se encontram com base nos direitos humanos e no relacionamento de respeito e igualdade de direitos entre as pessoas.

De acordo com Louro (2008b):

[...] se admitimos que a escola não apenas transmite conhecimentos, nem mesmo apenas só produz, mas ela também fabrica sujeitos, produz identidades étnicas, de gênero, de classe; se reconhecemos que essas identidades estão sendo produzidas através de relações de desigualdade; se admitimos que a escola está intrinsecamente comprometida com a manutenção de uma sociedade dividida e que faz isso cotidianamente, com nossa participação ou omissão; se acreditamos que a prática escolar é historicamente contingente e que é uma prática política, isto é, que se transforma e pode ser subvertida; e por fim, se não nos sentimos conformes com essas divisões sociais, então, certamente, encontramos justificativas não apenas para observar, mas, especialmente, para tentar interferir na continuidade dessas desigualdades (LOURO, 2008b, p. 86).

Ao "fabricar" esses sujeitos a escola coloca na sociedade indivíduos críticos, políticos e comprometidos com uma sociedade mais justa e igualitária ou pessoas que não possuem nenhuma dessas características e em nada vão influenciar na construção de uma sociedade melhor. Essa é uma escolha que a escola faz ao planejar e cumprir a sua missão como construtora de sujeitos. A escola, porém, não pode esperar que esta missão construtora ocorra a partir de ações macro e nem que venha de cima para baixo ou de 
fora para dentro. É urgente, segundo Louro (2008b), exercitar a transformação a partir de práticas cotidianas mais imediatas e banais, nas quais estamos todas irremediavelmente envolvidas, sem desconsiderar que os movimentos coletivos mais amplos sejam certamente importantes, no sentido de interferir na formulação de políticas públicas educacionais que permitam ver e lidar com as diferenças e a perpetuação das desigualdades sociais.

Para que a escola possa efetivamente atuar nesta intervenção e trabalhar com as diferenças, precisa oportunizar outras discussões envolvendo a sexualidade, a exemplo das múltiplas expressões de gênero, incluindo travestilidade, transexualidade e também a diversidade sexual.

O processo de ocultamento de determinados sujeitos pode ser flagrantemente ilustrado pelo silenciamento da escola em relação aos/as homossexuais. No entanto, a pretensa invisibilidade dos/das homossexuais no espaço institucional pode se constituir, contraditoriamente, numa das mais terríveis evidências da implicação da escola no processo de construção das diferenças. De certa forma, o silenciamento parece ter por fim "eliminar" esses sujeitos, ou, pelo menos, evitar que os/as alunos/alunas "normais" os/as conheçam e possam desejá-los. A negação e a ausência aparecem, nesse caso, como uma espécie de garantia da norma (LOURO, 2001, p. 89).

É evidente a importância de se promover uma mudança na forma como a escola lida com as questões de gênero e de diversidade sexual, pois o silenciamento citado por Louro (2001) estimula o preconceito e a homofobia, pelo fato da homossexual ser visto como aquela pessoa que não pode falar na escola da sua identificação sexual e quando fala, é vista como a "diferente" e tudo que a mesma representa na escola de bom ou de ruim é atribuído sempre a sua identificação sexual.

\section{Caminho da pesquisa}

Na realização de uma pesquisa onde se aborda gênero e sexualidade, as questões individuais e subjetivas interferem no trabalho da professora em sala de aula e, portanto, nada mais adequado do que utilizar a pesquisa qualitativa exploratória como parte integrante deste processo.

Considerando ainda o tipo de pesquisa como exploratória, no sentido atribuído por Gil (1999) que o define como um trabalho envolvendo levantamento bibliográfico, entrevistas com pessoas que tiveram (ou tem) experiências práticas com o problema pesquisado e análise de exemplos que estimulem a compreensão. Possui também este MARGENS - Revista Interdisciplinar

Dossiê: Corpo, Gênero e Sexualidade Versão Digital - ISSN: 1982-5374

VOL.11. N. 17. Dez 2017. (p. 28-43) 
trabalho a finalidade básica de desenvolver, esclarecer e modificar conceitos e ideias para a formulação de abordagens posteriores. Dessa forma, este tipo de estudo visa proporcionar um maior conhecimento para a pesquisadora acerca do assunto a fim de que se possa formular outras problemáticas, desdobrar outros questionamentos e criar hipóteses que possam ser pesquisadas por estudos posteriores.

A pesquisa foi realizada em Escolas da Rede Municipal em Jequié- Bahia, que tem a disciplina Educação para Sexualidade como componente curricular. Para a coleta de dados desta pesquisa foram utilizados 02 instrumentos: formulário de informações pessoais e profissionais das entrevistadas; e entrevista semiestruturada.

O formulário continha informações pessoais e profissionais consideradas relevantes para a pesquisa e, a partir desses dados, foi feita a seleção para as entrevistas. Esse formulário foi preenchido por 19 professoras e 01 professor que trabalha com a disciplina Educação Para Sexualidade nas 12 escolas pesquisadas da rede municipal de ensino de Jequié/Bahia. Para a entrevista, realizada com 10 professoras e 01 professor, foi elaborado um roteiro com 18 perguntas abertas que foram gravadas e, em seguida, transcritas e analisadas. Visando preservar a identidade do/das entrevistado/as fizemos a identificação com nomes de Deuses da Mitologia Grega.

De acordo com Fraser e Gondim (2004), a entrevista na pesquisa qualitativa, ao privilegiar a fala dos atores sociais, permite atingir um nível de compreensão da realidade humana que se torna acessível por meio de discursos, sendo apropriada para investigações cujo objetivo é conhecer como as pessoas percebem o mundo.

Esta relação entre a entrevista e a produção dos discursos nos fez optar por utilizar como método de análise de dados a Análise de Discurso (AD), na perspectiva foucaultiana.

Quando estudamos as linguagens, as concepções individuais e de grupos e os textos, que fazem parte diretamente dos discursos, é importante que se faça uma análise detalhada e profunda, considerando-se os vários tipos de discursos e a forma como estes são produzidos.

\section{As (im)possibilidades das discussões sobre sexualidade em um componente curricular específico}

Um dos questionamentos feito às professoras foi entender se, anteriormente à inclusão de um componente curricular específico, traziam discussões sobre sexualidade 
em suas aulas, independente da disciplina que lecionavam. Elas relataram que essas discussões eram feitas pontual e superficialmente, atreladas às discussões biológicas. A falta de tempo e, no caso de Ciências e Biologia, excesso de conteúdos que tinham de cumprir inviabilizava um trabalho mais apurado com sexualidade e, por este motivo, todas consideraram relevante a implantação da disciplina. Furlani (2013) já relatava que o ensino da sexualidade nos espaços escolares foi marcado por atividades pontuais e descontínuas que, geralmente, ocasionavam desmotivação e frustração nas crianças e adolescentes, pois o trabalho sempre era interrompido.

É importante perceber que as discussões sobre gênero e sexualidade, ao se configurarem como componente curricular deixam de "disputar espaços" com outras questões. Esta disputa de espaço relaciona-se com as questões de poder inscritas nos currículos do qual fala Silva (2001). Para ele, existem diversas questões a serem respondidas ao se elaborar um currículo e uma delas é identificar qual conhecimento ou saber é considerado importante ou válido ou essencial para ser considerado parte do currículo. Para algumas entrevistadas:

Com certeza quando se tornou disciplina foi melhor, a gente trabalhava, assim, com coisa pontual, na questão biológica, mais biológica, aí você estava ali falando daquele determinado assunto, aí você fazia um gancho, agora que você tá trabalhando aí você só vê aquele dia específico, por exemplo, às vezes não tinha nem espaço para eles fazerem perguntas e agora com a disciplina há oportunidade para isso (grifo nosso - TEIA).

Com certeza dá pra abrir mais um leque, um leque diferente. porque, por exemplo, devia ter matemática e geometria, porque a gente acaba deixando a geometria de lado e o aluno não vê geometria, já com essa disciplina não, a gente pode ver todos os assuntos numa turma, vamos dizer, mais aberta, mais abrangente, não é aquela coisa tão resumida, que tem um currículo a cumprir, uma carga horária a cumprir, não é a mesma coisa (grifo nosso - REIA).

Os depoimentos das professoras apontaram a relevância da disciplina por proporcionar um espaço de discussão não encontrado em outro componente curricular e que não seria possível discutir mais profundamente os temas escolhidos de forma transversal. As ideias das entrevistadas em relação à importância deste espaço corroboram com a visão de Nunes e Silva (2000) e Figueiró (2000) ao falarem da resistência das professoras e da inviabilidade dos temas transversais no que se refere à abordagem de 
gênero e sexualidade, especialmente devido à precariedade na formação e na atuação profissional. Para Figueiró (2006), o espaço da sexualidade enquanto tema transversal ocupa uma posição marginal no currículo em virtude, sobretudo, por não ser considerada uma questão prioritária; não ser posta em prática em muitas escolas, ficando restritas às iniciativas individuais de docentes e por ser uma temática considerada por muitos profissionais da educação com algo restrito à família.

Em geral, para as professoras, este espaço delimitado pela criação da disciplina proporciona um protagonismo nos/as estudantes ao oportunizá-los/as questionarem e exporem os seus pensamentos, mesmo que seja, inicialmente, restrito aos aspectos biológicos e também pode potencializar a abordagem de outras questões para além de temas como gravidez na adolescência e doenças sexualmente transmissíveis.

Contudo, em alguns casos, a existência da disciplina pode se tornar uma armadilha, pois os/as demais docentes não se sentem responsáveis por essas discussões, já que o trabalho com sexualidade é considerado difícil para muitos/as professores/as e estes/as, em várias situações, terminam por se eximirem dessas discussões. Para algumas entrevistadas, a existência da disciplina, a legitima como o único espaço de discussão da sexualidade, desobrigando aos/as demais professores/as a falarem e debaterem sobre aspectos que envolvem esta temática.

Eu acho assim, que depois que passou a ter essa disciplina só o professor de orientação sexual acaba trabalhando esse tema, o que deveria ser um tema transversal, depois que colocou a disciplina, acha que é só obrigação do professor de sexualidade falar sobre a temática (grifo nosso - HÉSTIA).

Esses outros elementos dão margem a uma ampla discussão, pois, se por um lado a implantação da disciplina configura-se como um espaço de discussões, por outro, pode aprisioná-las nesse lugar, dificultando os seus desdobramentos em outros momentos.

Há outros aspectos importantes em relação à compreensão das professoras sobre a disciplina que podem ser evidenciados, especialmente, quando algumas entrevistadas colocam que na escola, o/a estudante pode se sentir mais livre para falar do que na família, como se houvesse, de certa forma, uma transferência de responsabilidade, pois elas visualizam que os familiares não conseguem dar conta destas questões.

Porque os jovens geralmente não têm maturidade pra conversar com os pais, e os pais também, pela criação, às vezes têm vergonha, não 
conversam sobre certos assuntos, com os filhos, então é importante que a disciplina seja desenvolvida pra que eles tenham informações que não encontram em casa (grifo nosso - TESSALA).

A afirmação de que as famílias não têm condições de falar sobre sexualidade e que a escola a substitui neste papel foi muito presente nas entrevistas. Porém, generalizar essa ideia e atribuir esta "incapacidade" a todas as famílias como forma de justificar a importância da disciplina é arriscado. Por outro lado, destaca-se a preocupação das docentes em ter o aval da família para desenvolverem o trabalho de sexualidade na escola. Entra aqui um jogo nessa relação entre família e escola.

[...] quando a gente implantou logo aqui, a gente chamava os pais, dizia a eles o que era essa disciplina, qual era a importância de trabalhar essa disciplina, então nunca tive nenhum problema de nenhum pai dizer: "Ah, professora, a senhora tá ensinando sexo a meu filho, meu filho tá ficando assim em casa". Não, ao contrário, muitos já chegaram aqui e elogiaram que os filhos estavam mudando, que estavam com outra postura... (grifo nosso - REIA).

[... ] eu já tive casos de pais que chegaram lá pro diretor e falaram que... "Ah, por que essa disciplina?". Ai perguntaram se essa disciplina não vai acabar incentivando, né, o filho ou a filha dele a pensar nessas coisas antes da hora, né... Já teve casos assim (grifo nosso - ASTÉRIA).

Essa preocupação em relação à aprovação ou não da família na realização do trabalho escolar envolvendo sexualidade deve ser vista com cuidado para que a escola não se torne refém, fazendo só aquilo que seja "autorizado" pelos familiares. Por que a família não é consultada quando se trata de outras questões? De acordo com Eros (único professor da entrevista), esse consentimento da família é solicitado também na distribuição dos preservativos, pois se entende que isso possa significar um incentivo ao sexo.

O "estado de alerta perpétuo", a que Foucault (1998) se referiu em relação à sexualidade, fez com que, historicamente, a inserção dessas discussões no espaço escolar tivesse uma intenção de normatizar as práticas e colocar o sexo em discurso para tomar conhecimento do que estava se falando. Destaca-se pelas entrevistadas a preocupação com este "estado de alerta" e com a relação entre o exercício da sexualidade e suas consequências. 
Isto foi percebido quando Eros expressou certa preocupação em acompanhar as atitudes dos/as estudantes fora do espaço escolar, por morar no mesmo distrito em que a escola está localizada. O seu discurso destaca não só a preocupação com a postura dos/das alunos/as como também certa inquietude no que se refere à imagem que seus/suas discentes construirão dele. Nesse caso a vigilância é em mão dupla.

[...] às vezes eu interfiro até na vida deles lá fora, eu falo estou de olho lá fora viu? Então já chega na sala assim: O professor está lá, sai daqui dizendo que está de olho em mim lá fora então eu tenho que passar para eles uma imagem (grifo nosso - EROS).

A vigilância e controle em relação à sexualidade das crianças e adolescentes, conforme Foucault (1988) se inicia no século XVIII. A partir desse período preocupouse em regular o sexo por intermédio de discursos públicos. Não se deixou de falar do sexo, passou-se a um estado de alerta mediante prescrições e punições. Segundo o autor:

O espaço da sala, a forma das mesas, o arranjo dos pátios de recreio, a distribuição dos dormitórios (com ou sem separações, com ou sem cortina), os regulamentos elaborados para a vigilância do recolhimento e do sono, tudo fala da maneira mais prolixa da sexualidade das crianças (FOUCAULT, 1988, p. 34).

Desse período para cá, a pedagogia e a medicina passaram a combater a masturbação em crianças e adolescentes, perseguindo o que pudesse incitá-los ou propiciá-los. Também foram construídos discursos corretivos e se implantou na família fundamentos para um regime médico-sexual (FOUCAULT, 1988).

Foi possível perceber também que, de certa forma ocorre uma desestabilização e um receio em não ter sempre as respostas corretas para todas as coisas, como nos fizeram acreditar que seria função dos/as educadores/as. Discutir temas que foram citados nas falas acima como polêmicos, a exemplo do casamento entre pessoas do mesmo sexo e aborto, requer que o/a educador/a esteja aberto/a e receptivo/a ao que é trazido pelos/as alunos/as sem emitir juízo de valor, respeitando as individualidades e evitando uma visão moralista, religiosa, familiar ou pessoal.

Surgem também outras questões consideradas importantes pelas entrevistadas para a adolescente.

[...] trabalhamos com a questão da afetividade e a questão da autoestima e quando a gente trabalhou com a auto-estima, nós percebemos 
claramente uma mudança no comportamento desses alunos [...] Depois a gente trabalha com a questão da afetividade, porque não dá pra você falar de sexualidade, se o aluno não tiver consciência do que é afetividade, da importância da afetividade na vida dele pra que ele exerça a sua sexualidade com plenitude [...] Eu percebo claramente a diminuição da homofobia, a questão do bullying tem diminuído bastante [...] o trabalho com a questão da prevenção das drogas, porque a gente tem que trabalhar [...] (TETIS).

[...] entro também na questão da pornografia, do erotismo, a questão da influência da mídia, a questão da prostituição, a valorização do corpo, drogas, e aí... a gente vai dando sequência nisso aí [...] a gente faz, assim, um trabalho voltado pra a questão do ficar, do namorar, a diferença (REIA).

[...] e agora a gente tá trabalhando com masturbação, virgindade, essas questões (TESSALA).

Percebemos, pelos discursos das entrevistadas, que a entrada desses outros temas só é possibilitada a partir do momento em que a sexualidade passa a fazer parte do currículo. Foi possível identificar o surgimento desses temas nas discussões, porém, não foi propósito deste estudo acompanhar a forma como os mesmos são discutidos.

\section{Considerações finais}

Nos últimos anos, para a nossa sociedade, a sexualidade, especialmente, em se tratando de adolescentes, além de ser vista pelo viés da moralidade, é identificada como um problema de saúde pública em que se faz necessário um olhar voltado para a prevenção de tudo que seja consequência do exercício da sexualidade. A escola, por ser o local onde os/as adolescentes passam a maior parte do seu tempo e onde são construídas diversas relações, é indicada como um local privilegiado para se discutir sexualidade e todas as outras questões do seu entorno, como também para implantação de políticas públicas que promovam a saúde de crianças e adolescentes.

No espaço da escola a sexualidade é encarada como resultante da ação dos hormônios sexuais, ou seja, é discutida pelo viés da disciplina de Ciências sendo considerada como a reunião de diferentes saberes científicos vindos, sobretudo, da medicina e da biologia. Por essas razões, há uma preocupação em torno da gravidez na adolescência e das DST/AIDS que servem para justificar a inserção da temática da sexualidade nos currículos e projetos escolares visando a incorporação da perspectiva preventiva. 
Com base no pressuposto de que o espaço escolar é relevante para as discussões a respeito da sexualidade, me propus a realizar essa pesquisa em Jequié-BA, município onde essas discussões se configuram como componente curricular específico da base diversificada nos anos finais do Ensino Fundamental em todas as escolas da rede municipal, sendo denominada Educação para Sexualidade.

Ressalto não ter a intenção de legitimar e nem formular opiniões defendendo ou não a implantação de uma disciplina em que sejam discutidas as questões referentes à sexualidade, porém, quero destacar que, independente da forma como isso aconteça, é importante que a escola proporcione esse espaço de discussão.

Ao utilizar a análise do Discurso na perspectiva foucaultiana para explorar as entrevistas busquei compreender como a sexualidade tem sido tratada na prática a partir das falas do/das professor/as entrevistado/as. Destaco que a análise feita nas entrevistas não foi exaustiva para não perdermos o foco da investigação, portanto ela foi feita com o intuito de responder aos objetivos e a questão de estudo proposta neste trabalho.

É importante considerar que durante a pesquisa foi possível perceber que a criação de um espaço próprio de discussão, pode ser uma forma de controle daquilo que está sendo trabalhado na escola em termos de sexualidade, regulando-se as experiências sexuais das estudantes não pelo rigor das proibições, mas por meio de instruções e prescrições daquilo que é certo ou errado. Evidencia-se que a disciplina vai corrigir o que os/as alunos/as trazem.

Esta questão nos remete a visão da incitação ao discurso citada por Foucault (1988), em que o sexo é incitado a confessar-se e a manifestar-se por meio de múltiplas estratégias nas quais proliferam discursos que nos convidam incessantemente a falar sobre ele, utilizando a escola, a igreja, a família, o consultório médico e saberes da biologia, da psicologia, da medicina, da psiquiatria e da pedagogia. Saberes e poderes que, intensificando o desejo de saber mais sobre o sexo, impõem o lugar e o regime específico de verdade a partir de uma multiplicidade de discursos.

Diante disso, a disciplina visa proporcionar uma maior discussão sobre as temáticas da sexualidade, porém, com discursos pautados em temas, lugares e regimes de fala previamente concebidos e já formatados.

Apesar de a disciplina Educação para Sexualidade ter como foco a prevenção à gravidez na adolescência e às DST/Aids, há escapes que proporcionam o debate de outras questões que fogem a estas normatizações como gênero, diversidade sexual, homofobia, 
afetividade, auto-estima, prostituição e aborto, mesmo que ainda de maneira tímida. É interessante que essas “outras discussões” se ampliem evitando juízos de valor e conceitos morais e religiosos como acontece, por exemplo, quando se discute o aborto e a prostituição, onde os/as alunos/as normalmente são levadas a assumirem uma posição contrária desconsiderando os múltiplos fatores que envolvem essas situações.

Diante da falta de abertura para essas discussões os/as alunas que tenham vivenciado alguma situação de aborto ou de prostituição, por receio das reações que possam acontecer, não declaram isso de forma transparente o que poderia ser uma oportunidade de abertura para este diálogo.

Ao identificar e analisar as vantagens e desvantagens em trabalhar a sexualidade em um componente curricular específico ficou visível que o fato da disciplina proporcionar um espaço de discussão mais amplo, inclusive para abordagem de outras questões que escapam ao que é comum, pode se configurar como uma vantagem, pois essas outras discussões geralmente não ocorrem quando o assunto é pensado sob o viés de um tema transversal.

O que vemos, no entanto é que, ainda não temos uma política educacional concreta que atenda as necessidades básicas das professoras para o trabalho com os temas transversais e lidamos o tempo todo na escola com programas e projetos governamentais eventuais que, na maioria das vezes, são encerrados ou substituídos antes mesmo de se conseguir algum resultado.

Por outro lado, identificamos que este espaço fica delimitado no ambiente escolar como se fosse dever apenas do/da professor/a da disciplina a abordagem da sexualidade fazendo com que os demais se eximam desta responsabilidade; isto pode ser configurado como uma desvantagem da existência da disciplina. Nessa direção, é necessário o planejamento de ações que possam ofertar oportunidades para se discutir essas questões nas escolas, sendo ampliadas as responsabilidades dessas discussões para toda a escola e não para professores/as específicos.

Em suma, o processo de construção desta pesquisa nos faz pensar que a sexualidade pode ser trabalhada na escola como prática de liberdade de expressão em que o/a discente veja no/a professor/a muito mais do que alguém que lhe trará apenas informações relacionadas às questões de sexualidade, mas a pessoa com quem eles/elas possam ter abertura para abordar as mais diversas questões referentes a esta temática. 
É inegável que diante de todas as dificuldades apresentadas, para que as discussões de sexualidade aconteçam realmente, faz-se necessário que se busquem alternativas que tornem viáveis este trabalho na escola, seja como tema transversal ou na forma de componente curricular específico. É importante o reconhecimento das dificuldades encontradas pelos/pelas professores/as, mas, é também necessário que esta percepção impulsione ações concretas e efetivas visando minimizá-las, principalmente em relação às condições do trabalho docente e à formação inicial e continuada.

Este trabalho também poderá suscitar outras pesquisas na área, onde seria interessante analisar as concepções dos/as alunos/as das turmas que possuem a disciplina Educação para Sexualidade e a visão deles/as sobre a existência da disciplina.

O resultado obtido a partir da análise das entrevistas poderá servir para uma revisão da proposta pela Secretaria Municipal de Educação onde se busque sanar as dificuldades, sendo necessário que a disciplina seja vista como importante para o desenvolvimento pessoal dos/das alunas e, dessa forma, seja feito um maior acompanhamento buscando dar um maior apoio em termos de material e de formação das professoras para que os/as mesmos/as se sintam amparadas no trabalho com a disciplina.

\section{Referências}

ALTMANN, H. Orientação sexual em uma escola: recortes de corpo e gênero. Cadernos Pagu (21), p. 281-315, 2003.

BRASIL. Conselho Nacional de Educação / Câmara de Educação Superior. Diretrizes Curriculares Nacionais para os Cursos de Ciências Biológicas. Brasília: MEC, 2001.

FIGUEIRÓ, M. N. D. Educação Sexual: como ensinar no espaço da escola. Revista Linhas. Florianópolis, v. 07, n. 01, p. 1-21, jan/jun. 2006.

M. N. D. A viabilidade dos temas transversais à luz da questão do trabalho docente. PSI: Revista de Psicologia Social e Institucional, vol. 2, $\mathrm{n}^{\circ} 1$. Londrina, jun., pp. 17-36. 2000.

FOUCAULT, M. História da Sexualidade. Vol. 1: A vontade de saber. $11^{\text {a }}$ Ed. Rio de Janeiro: Graal, 1988.

Michael. A Ordem do discurso. São Paulo: Edições Loyola, 1998.

FRASER, M. T. D. e GONDIM, S. M. G. DA FALA DO OUTRO AO TEXTO NEGOCIADO: DISCUSSÕES SOBRE A ENTREVISTA NA PESQUISA QUALITATIVA. Universidade Federal da Bahia. Paidéia, 14 (28), 139-152, 2004.

GIL, Antonio Carlos. Métodos e técnicas de pesquisa social. São Paulo: Atlas, 1999. 
LIRA, A., JOFILI, Z. O tema transversal orientação sexual nos PCN e a atitude dos professores: convergentes ou divergentes? REMPEC-Revista Ensino, Saúde e Ambiente, v.3, n.1, p. 22-41, abril, 2010.

LOURO, G. L. Teoria Queer: Uma Política Pós-Identitária para a Educação. In: Revista Estudos Feministas. V.9 n.2 Florianópolis, 2001.

G. L. Gênero, sexualidade e educação: uma perspectiva pós-estruturalista. Ed. Petrópolis, RJ: Vozes, 2008b.

MARTINS, E. de F., HOFFMANN, Z. Os papéis de gênero nos livros didáticos de ciências. Revista Ensaio, v.9, n.1, 2007.

NUNES, C. e SILVA, E. A educação sexual da criança: Subsídios teóricos e propostas práticas para uma abordagem da sexualidade para além da transversalidade. Campinas: Autores Associados, 2000.

SANTANA, M.C. de., WALDHELM, M. de C. Abordagem da sexualidade humana em livro didático de ciências- Desvelando os bastidores de uma proposta. REMPEC-Revista Ensino, Saúde e Ambiente, v.2, n.2, p. 2-20, agosto, 2009.

SANTOS, W.B., CARDOSO, R., ALMEIDA, J. da S.M., MOREIRA, F.A. Educação sexual como parte curricular da disciplina de biologia e auxilio a adolescentes: Dificuldades e desafios. Revista Experiência em Ensino de Ciências, v.6, n.1, p.205216. 2011.

SILVA T. T. Documentos de identidade: uma introdução às teorias do currículo. Belo Horizonte: Autêntica, 2001. 